\title{
Manifestações articulares nas viroses exantemáticas
}

\author{
Joint complaints in exanthematic diseases
}

\author{
Solange Artimos de O liveira, Luís A.B. Camacho, Lílian Rachel Bettini, Daniele \\ Guerreiro Fernandes, Nathalia A.C. Gouvea, Roberto A.Q. Barros, \\ Sérgio Setúbal e Marilda Mendonça Siqueira
}

\begin{abstract}
Resumo $A$ freqüência de manifestações articulares foi avaliada em 251 pacientes com diagnóstico clínico e laboratorial (detecção de lgM por ensaio imunoenzimático) de virose exantemática. As artropatias (artralgia e/ou artrite) foram mais observadas nos casos de dengue $(49 \%)$ e de rubéola $(38,2 \%)$ do que naqueles com parvovirose humana $(30 \%)$ e sarampo (28,1\%). Com exceção do sarampo, as artropatias predominaram nos adultos $\geq 15$ anos de idade), sendo tal diferença estatisticamente significativa. A ocorrência maior de artropatias em adultos foi mais evidente nos pacientes com parvovirose (75\%), rubéola (65\%) e dengue $(57,7 \%)$ do que naqueles com sarampo (31\%). As queixas articulares também predominaram nos pacientes do sexo feminino para todas as viroses avaliadas. Os resultados encontrados demonstram o freqüente acometimento articular nas doenças estudadas, e indicam a necessidade de comprovação laboratorial para o diagnóstico diferencial entre elas.
\end{abstract}

Palavras-chaves: Viroses exantemáticas. Artralgia. Artrite. Exantema.

\begin{abstract}
The frequency of arthropathy was evaluated in 251 patients with clinical and serological diagnosis (specific lgM detection by enzyme immunoassay) of exanthematic disease. Arthropathy (arthralgia and/or arthritis) was more frequent in dengue fever (49\%) and rubella (38.2\%) cases than in human parvovirus (30\%) and measles (28.1\%) cases. Except for measles cases, joint complaints prevailed in adults ( $\geq 15$ years of age) and this difference was significant. The higher frequency of arthropathy in adults was more evident in human parvovirus (75\%), rubella (65\%) and dengue fever (57.7\%) cases than in measles cases (31\%). Arthropathy was also more frequent in females for all rash diseases studied. The results of this study showed the high occurrence of joint complaints in the diseases described here and the importance of laboratory confirmation for their differential diagnosis.
\end{abstract}

Key-words: Exanthematic diseases. Arthralgia. Arthritis. Exanthema.

\footnotetext{
Disciplina de Doenças Infecciosas e Parasitárias, Faculdade de Medicina da Universidade Federal Fluminense, Niterói, RJ. Departamento de Epidemiologia da Escola Nacional de Saúde Pública e Departamento de Virologia, Fundação Oswaldo Cruz, Rio de Janeiro, RJ.

Financiado pelo CNPq, Processo № 52-0689/96-8

Endereço para correspondência: Profa. Solange Artimos de Oliveira. Disciplina de Doenças Infecciosas e Parasitárias. R. Marquês do Paraná 303, 2ำ andar, 24030-210 Niterói, RJ.

Fax: $5521719-7262$

Recebido para publicação em 21/5/98
} 
Diversos agentes virais têm sido implicados na ocorrência aguda ou crônica de manifestações articulares. Em geral, tais afecções são mais observadas em adultos do que em crianças 4521. A artralgia ocorre com mais freqüência do que a artrite, e ambas são usualmente migratórias e de curta duração, geralmente desaparecendo sem deixar comprometimento articular residual 15 . Todavia, em alguns casos, tais manifestações podem persistir durante meses, ou mesmo anos após o quadro inicial 14.

A fisiopatogenia das lesões articulares causadas pelos vírus ainda não está completamente esclarecida. Para alguns autores, na fase aguda da doença tais lesões poderiam ser mediadas por complexos imunes 17 , coincidindo, portanto, com a indução da resposta de anticorpos, duas a três semanas após a infecção20. Na artrite crônica, vários mecanismos têm sido propostos, entre eles a persistência do agente viral no tecido e/ou no fluido sinovial2 13 .

Dentre os principais agentes virais causadores de artropatia estão o vírus da rubéola15 1619 do dengue 131822 e da parvovirose humana5 21. Em menor proporção, tais manifestações podem ser causadas por outros vírus, a saber: EpsteinBarr, citomegalovírus, varicela-zoster, hepatite $B$, echovírus, coxsackie $B$, herpes simplex, entre outros ${ }^{15}$. Além das causas virais, outras doenças podem evoluir com manifestações articulares e "rash" cutâneo como, por exemplo, a artrite reumatóide 5 , a doença de Lyme, a febre reumática e a meningococcemia 15 , justificando a importância do diagnóstico diferencial entre as mesmas e, como conseqüência, a introdução da terapêutica adequada.

Várias são as citações encontradas na literatura mundial sobre a ocorrência de manifestações articulares nas viroses exantemáticas, principalmente quando relacionadas à parvovirose humana e à rubéola. No entanto, tal fato ainda é pouco estudado em nosso meio. Este trabalho tem como objetivo estudar a freqüência das afecções articulares nas viroses exantemáticas, abordando especialmente àquelas apresentadas durante a evolução de casos de parvovirose, rubéola, dengue e sarampo.

\section{MATERIAL E MÉTODOS}

População de estudo. No período de janeiro de 1994 a fevereiro de 1998, foi realizado um estudo para investigação etiológica das viroses exantemáticas no Serviço de Doenças Infecciosas e Parasitárias do Hospital Universitário Antonio Pedro e nos Centros de Saúde Santa Rosa e Carlos Antonio da Silva, Niterói, Rio de Janeiro. Dos 380 pacientes atendidos, 251 apresentavam IgM específica positiva para uma das doenças a serem estudadas, sendo então incluídos na pesquisa. Um questionário contendo dados pessoais, achados clínicos e epidemiológicos foi especialmente desenhado para o estudo. Foram investigados sinais e sintomas de acometimento articular (artralgia e/ou artrite) e descritas as articulações mais atingidas. Os pacientes com $\geq 15$ anos foram considerados como adultos.

Coleta das amostras sangüíneas. As amostras sangüíneas, coletadas por venopunção, foram acondicionadas em tubos de vidro estéreis, sem anticoagulante. Os soros, separados do coágulo por centrifugação, foram transferidos para frascos rosqueados e estocados a $-20 \circ \mathrm{C}$ até a realização dos testes laboratoriais.

Testes laboratoriais. Os testes laboratoriais empregados para o diagnóstico das viroses estudadas através da detecção de lgM específico foram: a) sarampo - ensaio imunoenzimático (EIE) por captura de IgM7; b) rubéola - EIE por captura de IgM (Rubezyme M, Abbot Laboratories, Chicago, USA); c) parvovirose humana - EIE por captura de IgM6; d) dengue EIE por captura de IgM11 12.

Testes estatísticos. A significância estatística das diferenças entre as proporções foi avaliada pelo teste do qui-quadrado $\left(\chi^{2}\right)$ e pelo Teste Exato de Fisher.

\section{RESULTADOS}

Dos 380 pacientes com doença exantemática, atendidos nos locais de estudo, 251 apresentavam nos testes laboratoriais empregados IgM específica para uma das viroses estudadas: dengue: 100 casos; rubéola: 89 casos; sarampo:
32 casos; parvovirose humana: 30 casos. A distribuição etária do grupo estudado de acordo com a doença apresentada é discriminada na Tabela 1. 
Tabela 1 - Distribuição etária dos pacientes de acordo com a doença estudada.

\begin{tabular}{|c|c|c|c|c|c|c|c|c|c|c|}
\hline \multirow{3}{*}{$\begin{array}{l}\text { Faixa etária } \\
\text { (anos) }\end{array}$} & \multicolumn{10}{|c|}{ Doença } \\
\hline & \multicolumn{2}{|c|}{ dengue } & \multicolumn{2}{|c|}{ rubéola } & \multicolumn{2}{|c|}{ sarampo } & \multicolumn{2}{|c|}{ parvovirose } & \multicolumn{2}{|c|}{ total } \\
\hline & $\mathrm{n}^{\circ}$ & $\%$ & $\mathrm{n}^{0}$ & $\%$ & $n^{0}$ & $\%$ & $\mathrm{n}^{0}$ & $\%$ & $\mathrm{n}^{\circ}$ & $\%$ \\
\hline$<1$ & 2 & 2 & 3 & 3,3 & 2 & 6,2 & - & - & 7 & 2,8 \\
\hline $1-4$ & 1 & 1 & 21 & 23,6 & 1 & 3,1 & 5 & 16,7 & 28 & 11,2 \\
\hline $5-9$ & 7 & 7 & 17 & 19,1 & - & - & 13 & 43,4 & 37 & 14,7 \\
\hline $10-14$ & 12 & 12 & 8 & 9 & - & - & 4 & 13,3 & 24 & 9,6 \\
\hline $15-19$ & 7 & 7 & 15 & 16,9 & 3 & 9,4 & 1 & 3,3 & 26 & 10,4 \\
\hline $20-29$ & 28 & 28 & 13 & 14,6 & 22 & 68,8 & 2 & 6,7 & 65 & 25,9 \\
\hline $30-39$ & 23 & 23 & 8 & 9 & 4 & 12,5 & 4 & 13,3 & 39 & 15,5 \\
\hline $40-49$ & 15 & 15 & 4 & 4,5 & - & - & 1 & 3,3 & 20 & 8 \\
\hline $50-59$ & 4 & 4 & - & - & - & - & - & - & 4 & 1,6 \\
\hline $60-69$ & 1 & 1 & - & - & - & - & - & - & 1 & 0,3 \\
\hline Total & 100 & 100 & 89 & 100 & 32 & 100 & 30 & 100 & 251 & 100 \\
\hline
\end{tabular}

As manifestações articulares (artralgia e/ou artrite) foram observadas em $49,0 \%$ dos casos de dengue, em $38,2 \%$ daqueles com rubéola e, em menor freqüência, nos casos com parvovirose humana e sarampo, respectivamente, 30,0\% e $28,1 \%$ (Tabela 2). As diferenças entre essas proporções, embora de magnitude expressiva, não alcançaram significância estatística $\left(\chi^{2}=6,50\right.$; $p=0,089$ ).

$\mathrm{Na}$ Tabela 3 estão discriminadas as freqüências das artropatias nas doenças estudadas de acordo com a faixa etária. Com exceção do sarampo, as manifestações articulares predominaram nos adultos (pacientes com $\geq 15$

Tabela 2 - Freqüência de manifestações articulares em pacientes com viroses exantemáticas.

\begin{tabular}{|c|c|c|c|c|c|}
\hline \multirow[t]{3}{*}{ Doença } & \multicolumn{5}{|c|}{ Manifestações articulares } \\
\hline & \multicolumn{2}{|c|}{$\operatorname{sim}$} & \multicolumn{2}{|c|}{ não } & \multirow{2}{*}{$\begin{array}{c}\text { total } \\
\mathrm{n}^{\circ}\end{array}$} \\
\hline & $\mathrm{n}^{\circ}$ & $\%$ & $\mathrm{n}^{0}$ & $\%$ & \\
\hline Dengue & 49 & 49,9 & 51 & 51 & 100 \\
\hline Rubéola & 34 & 38,2 & 55 & 61,8 & 89 \\
\hline Sarampo & 9 & 28,1 & 23 & 71,9 & 32 \\
\hline Parvovirose & 9 & 30 & 21 & 70 & 30 \\
\hline
\end{tabular}

$\chi^{2}=6,61 ; p=0,0856$.

Tabela 3 - Freqüência de manifestações articulares em pacientes com viroses exantemáticas de acordo com a faixa etária.

\begin{tabular}{|c|c|c|c|c|c|c|c|c|c|}
\hline \multirow[t]{3}{*}{ Doença } & \multicolumn{4}{|c|}{$<15$ anos } & \multicolumn{4}{|c|}{$\geq 15$ anos } & \multirow{3}{*}{$p$ - valor } \\
\hline & \multicolumn{2}{|c|}{$\operatorname{sim}^{*}$} & \multicolumn{2}{|c|}{ total } & \multicolumn{2}{|c|}{$\operatorname{sim}^{* *}$} & \multicolumn{2}{|c|}{ total } & \\
\hline & $\mathrm{n}^{0}$ & $\%$ & $\mathrm{n}^{0}$ & $\%$ & $\mathrm{n}^{\circ}$ & $\%$ & $\mathrm{n}^{0}$ & $\%$ & \\
\hline Dengue & 4 & 18,2 & 22 & 100 & 45 & 57,7 & 78 & 100 & 0,0024 \\
\hline Rubéola & 8 & 16,3 & 49 & 100 & 26 & 65 & 40 & 100 & 0,000 \\
\hline Sarampo & - & - & 3 & 100 & 9 & 31 & 29 & 100 & 0,5409 \\
\hline Parvovirose & 3 & 13,6 & 22 & 100 & 6 & 75 & 8 & 100 & 0,0031 \\
\hline Total & 15 & 15,6 & 96 & 100 & 86 & 55,5 & 155 & 100 & - \\
\hline
\end{tabular}

${ }^{\star} \chi^{2}=0,75 ; p=0,8616{ }^{* \star} \chi^{2}=9,87 ; p=0,0197$.

anos de idade), sendo tal diferença estatisticamente significativa. A ocorrência maior de artropatias em adultos foi mais evidente nos pacientes com parvovirose $(75,0 \%)$, rubéola $(65,0 \%)$ e dengue $(57,7 \%)$, do que naqueles com sarampo $(31,0 \%)\left(\chi^{2}=9,87 ; p=0,019\right)$. $\mathrm{Em}$ crianças, a freqüência de artropatias não diferiu substancialmente entre as viroses, exceto o sarampo, cuja análise foi prejudicada pelo pequeno número de casos.

As artropatias predominaram nos pacientes do sexo feminino para todas as viroses avaliadas (Tabela 4), embora a diferença tenha sido estatisticamente significativa somente no grupo de 
dengue. Também para os gêneros separadamente o dengue produziu a maior freqüência de artropatias, embora as diferenças não tenham sido estatisticamente significantes (Tabela 4).

Tabela 4 - Freqüência de manifestações articulares em pacientes com viroses exantemáticas de acordo com o sexo.

\begin{tabular}{|c|c|c|c|c|c|c|c|c|c|}
\hline \multirow{4}{*}{$\begin{array}{l}\text { Doença } \\
\text { Dengue }\end{array}$} & \multicolumn{9}{|c|}{ Manifestações articulares } \\
\hline & \multicolumn{4}{|c|}{ sexo feminino } & \multicolumn{4}{|c|}{ sexo masculino } & \multirow{3}{*}{$\frac{p-\text { valor }}{0,0197}$} \\
\hline & \multicolumn{2}{|c|}{$\operatorname{sim}^{*}$} & \multicolumn{2}{|c|}{ total } & \multicolumn{2}{|c|}{$\operatorname{sim}^{* *}$} & \multicolumn{2}{|c|}{ total } & \\
\hline & 37 & 58,7 & 63 & 100 & 12 & 32,4 & 37 & 100 & \\
\hline Rubéola & 24 & 44,4 & 54 & 100 & 10 & 28,6 & 35 & 100 & 0,1998 \\
\hline Sarampo & 5 & 33,3 & 15 & 100 & 4 & 23,5 & 17 & 100 & 0,6998 \\
\hline Parvovirose & 8 & 40 & 20 & 100 & 1 & 10 & 10 & 100 & 0,2035 \\
\hline Total & 74 & 48,7 & 152 & 100 & 27 & 27,7 & 99 & 100 & - \\
\hline
\end{tabular}

${ }^{\star} \chi^{2}=4,95 ; p=0,1753 ;{ }^{\star *} \chi^{2}=2,15 ; p=0,5417$

As articulações mais atingidas foram, em ordem de freqüência, as interfalangianas proximais das mãos, joelho, interfalangianas dos pés, tornozelo, cotovelo e punho. Em menor proporção, outras articulações, tais como quadril e ombro, também foram afetadas. Em geral, o comprometimento articular era simétrico, de início agudo, durante a evolução da virose exantemática. A artralgia foi observada com maior freqüência que a artrite, e quando esta última estava presente, era caracterizada, principalmente, por dor, edema e enrijecimento das pequenas articulações dos dedos das mãos e, em menor proporção, das articulações dos dedos dos pés, do punho e do joelho.

Diferentemente dos casos de rubéola, dengue e parvovirose, em que os pacientes podiam apresentar simultaneamente artrite em algumas articulações e artralgia em outras, nos pacientes com sarampo apenas foi constatada a queixa de artralgia.

Em todos os pacientes, as artropatias evoluíram para cura completa, no prazo máximo de duas semanas, sem deixarem seqüelas residuais.

\section{DISCUSSÃO}

Embora citadas amplamente na literatura mundial, as manifestações articulares presentes na evolução das viroses exantemáticas ainda são pouco estudadas em nosso meio. Neste trabalho, apresentamos uma revisão da ocorrência de tais manifestações em casos de rubéola, parvovirose humana, dengue e sarampo, confirmados laboratorialmente pela detecção de IgM específica em amostras sangüíneas.

Em geral, as manifestações articulares descritas nos casos de rubéola 1619 , parvovirose 421 e dengue 318 ocorrem mais comumente em adultos, do sexo feminino, sendo a artralgia mais observada que a artrite. Além disso, o comprometimento articular é usualmente de curta duração, desaparecendo rapidamente sem deixar seqüelas residuais 15 . As articulações mais atingidas são: joelhos, tornozelos, cotovelos, interfalangianas proximais e metacarpofalangianas 101519 . Os resultados obtidos nesta pesquisa não foram diferentes dos citados na literatura. Verificou-se nos casos estudados uma poliartropatia aguda, de evolução simétrica, com predomínio em mulheres adultas.
Os locais mais lesados, para as doenças estudadas, foram as pequenas articulações das mãos e dos pés, joelhos, cotovelos e punhos. Diferentemente dos casos de rubéola, parvovirose e dengue, em que os pacientes apresentavam simultaneamente artralgia em algumas articulações e artrite em outras, naqueles com sarampo apenas foi constatada a queixa de artralgia.

Apesar da maior ocorrência de artropatias nos casos de dengue $(49 \%)$ e de rubéola $(38,2 \%)$ quando comparados com os de parvovirose humana $(30 \%)$ e de sarampo $(28,1 \%)$, tal diferença não se mostrou estatisticamente significativa. Ademais, tais percentuais não foram diferentes dos relatados na literatura para as doenças estudadas3 4516 .

Alguns comentários devem ser feitos em relação à presença de manifestações articulares no sarampo. Na literatura médica consultada tal manifestação não é descrita, provavelmente porque até alguns anos atrás, o sarampo atingia predominantemente crianças abaixo de cinco anos de idade 9 . Com o deslocamento da 
incidência da doença para faixas etárias mais elevadas, principalmente em adultos, como verificado nesta pesquisa, manifestações clínicas menos freqüentes em crianças passam a ser observadas.

$\mathrm{Na}$ casuística analisada, deve ser ressaltada a freqüência de poliartropatia encontrada nas crianças estudadas $(15,6 \%)$. Devido à relativa pouca gravidade das apresentações clínicas das viroses exantemáticas, em especial nos casos de rubéola e parvovirose, torna-se difícil obter amostras sangüíneas para o diagnóstico laboratorial. No entanto, outras doenças podem evoluir de modo semelhante, justificando a importância do diagnóstico diferencial. Como exemplo, pode ser citada a artrite reumatóide juvenil, que apresenta durante a evolução exantema, febre, linfoadenopatia, artrite 15 , podendo ser confundida inicialmente com um quadro viral.

Diferentemente do observado nesta pesquisa, várias são as citações encontradas na literatura sobre as manifestações articulares presentes na evolução da rubéola e da parvovirose em mulheres adultas que, em alguns casos, arrastamse por meses ou até anos 5821 . Tal sintomatologia pode ser indistingüível de outras doenças articulares, levando a diagnósticos errôneos e, conseqüentemente, à introdução de terapêutica inadequada. Nesta casuística, a ausência de artropatia de evolução crônica deve ser interpretada com cautela, tendo em vista o não acompanhamento por longo prazo dos pacientes avaliados.

Concluindo, os resultados desta pesquisa demonstram o freqüente acometimento das articulações nas viroses exantemáticas avaliadas, principalmente em adultos do sexo feminino, e indicam a necessidade de comprovação laboratorial para o diagnóstico diferencial entre elas e outras doenças que evoluem com comprometimento articular. Em nosso meio, a magnitude do problema torna-se mais evidente, devido a possibilidade da circulação dos vírus estudados em um mesmo período do ano, seja pelo próprio comportamento epidemiológico das doenças bem como pelas falhas nos programas nacionais criados para o seu controle.

\section{AGRADECIMENTOS}

Agradecemos as Dras. Jussara Pereira do Nascimento e Rita Maria Nogueira, do Departamento de Virologia da Fundação Oswaldo Cruz, pela realização das técnicas para o diagnóstico laboratorial da parvovirose e do dengue, respectivamente. Agradecemos, ainda, às equipes de médicos e aos demais funcionários do Serviço de Doenças Infecciosas e Parasitárias do Hospital Universitário Antonio Pedro da Universidade Federal Fluminense e dos Centros de Saúde Santa Rosa e Carlos Antonio da Silva da Fundação Municipal de Saúde de Niterói pelo atendimento aos pacientes.

\section{REFERÊNCIAS BIBLIOGRÁFICAS}

1. Adebajo AO. Dengue arthritis. British Journal of Rheumatology 35:909-910, 1996.

2. Chantler JK, da Roza DM, Bonnie ME., Reid GD, Ford DK. Sequential studies on synovial lymphocyte stimulation by rubella antigen, and rubella virus isolation in an adult with persistent arthritis. Annals of the Rheumatic Diseases 44: 564-568, 1985.

3. Cobra C, Rigau Pérez JG, Kuno G, Vordam V. Symptoms of dengue fever in relation to host immunologic response and virus serotype, Puerto Rico, 1990-1991. American Journal of Epidemiology 142:1204-1211, 1995.

4. Cohen BJ. Human parvovirus B19 and fifth disease. In: Mortimer PP (ed) Public Health Virology - 12 reports, 1st edition, Public Health Laboratory Service, London, p.130-143, 1986.

5. Cohen BJ. Parvovirus B19: an expanding spectrum of disease. British Medical Journal 311:1549-1552, 1995.
6. Cubel RCN, Alferes ACR, Cohen BJ, Nascimento JP. Application to immunoglobulin M capture hemadherence assays of hemagglutination of monkey erythrocytes by native and recombinant human parvovirus B19 antigen. Journal Clinical Microbiology 32:1997-1999, 1994.

7. Erdman DD, Anderson LJ, Adams DR, Stewart, JA, Markowitz, LE, Bellini, WJ. Evaluation of monoclonal antibody based capture enzyme immunoassays for detection of specific antibodies to measles virus. Journal Clinical Microbiology 29: 1466-1471, 1991.

8. Ford DK, Reid GD, Tingle AJ, Mitchell LA, Achulzer M. Sequential follow up observations of a patient with rubella associated persistent arthritis. Annals of the Rheumatic Diseases 51:407-410, 1992.

9. Fundação Nacional de Saúde (Brasil). Capacitação de pessoal para vigilância epidemiológica do sarampo. Módulo Instrucional I. Brasília, p. 1-77, 1992. 
10. Joseph PR. Fifth disease: the frequency of joint involvement in adults. New York State Journal of Medicine 86:560-563, 1986.

11. Kuno G, Gomez I, Gubler DJ. Detecting artificial antidengue IgM immune complexes using an enzyme-linked immunosorbent assay. American Journal of Tropical Medicine and Hygiene 36:153-159, 1987.

12. Nogueira RMR, Miagostovich MP, Lampe E, Souza RV, Zagne SMO, Schatzmayr HG. Dengue epidemic in the State of Rio de Janeiro, Brazil, 1990-1991. Co-circulation of dengue 1 and 2. Epidemiology and Infection 11:163170,1993

13. Ogra PL, Herd JK. Arthritis associated with induced rubella infection. Journal of Immunology 107:810, 1971.

14. Petty RE. Arthritis and viral infection. Journal of Pediatrics 113:948-949, 1988.

15. Petty RE, Tingle AJ. Arthritis and viral infection. Journal of Pediatrics 113:948-949, 1988.

16. Smith CA, Petty RE, Tingle AT. Rubella virus and arthritis. Rheumatic Disease Clinics of North America 13: 265274, 1987.
17. Schnitzer TJ. Viral arthritis. In: Kelley WN, Harris ED, Ruddy S, Sledge CB (eds) Textbook of Rheumatology. WB Saunders, Philadelphia, p. 1540-1556, 1985.

18. Schwartz E, Mendelson E, Sidi Y. Dengue fever among travelers. American Journal of Medicine 101:516-520, 1996.

19. Ueno Y. Rubella arthritis. Outbreak in Kyoto. The Journal of Rheumatology 21: 874-876, 1994.

20. Vergani D, Morgan-Capner P, Davis ET, Anderson AW, Ter DEH, Pattison JR. Joint symptoms, immune complexes, and rubella. Lancet 2:321-322, 1980.

21. White DG, Woolf AD, Mortimer PP, Cohen BJ, Blake DR, Bacon PA. Human parvovirus arthrophaty. Lancet 1: 419421, 1985.

22. Zagne SM, Alves VG, Nogueira RM, Miagostovich MP, Lampe E, Tavares W. Dengue hemorrhagic fever in state of Rio de Janeiro, Brazil: a study of 56 confirmed cases. Transactions of the Royal Society of Tropical Medicine and Hygiene 88:677-679, 1994. 